\title{
Rapid diagnosis of acute norovirus-associated gastroenteritis: evaluation of the Xpert Norovirus assay and its implementation as a 24/7 service in three hospitals in Jönköping County, Sweden
}

\author{
A. J. Henningsson ${ }^{1}$ • A. Nilsson Bowers ${ }^{1}$. J. Nordgren ${ }^{2}$ - M. Quttineh ${ }^{1}$. \\ A. Matussek ${ }^{1,3,4} \cdot$ S. Haglund ${ }^{1}$
}

Received: 13 February 2017 / Accepted: 3 May 2017 /Published online: 24 May 2017

(C) The Author(s) 2017. This article is an open access publication

\begin{abstract}
Noroviruses are a leading cause of epidemic and sporadic cases of acute gastroenteritis worldwide. The rapid diagnosis of norovirus infection is important for prompt infection control measures and may reduce the need for additional diagnostic testing. Here we evaluated the performance of the rapid Xpert Norovirus assay, and assessed the turn-around time (TAT) before and after the implementation of the analysis as a 24/7 service at all the three hospitals in Jönköping County, Sweden. We describe the implementation process which was performed in two steps during 2014. A total number of 276 clinical samples (stool and vomitus) from patients with symptoms of acute gastroenteritis were included in 2014-2015. The samples were analysed with the Xpert Norovirus assay and the already existing routine method: an in-house reverse transcription real-time PCR. Samples showing discrepant results with the two assays were further analysed by a third PCR method. The Xpert Norovirus assay performed well with a sensitivity of $100 \%$ and a specificity of $93 \%$ compared to the gold
\end{abstract}

Electronic supplementary material The online version of this article (doi:10.1007/s10096-017-3005-9) contains supplementary material, which is available to authorized users.

A. J. Henningsson

anna.jonsson.henningsson@rjl.se

1 Clinical Microbiology, Laboratory Medicine, Region Jönköping County, S-551 85 Jönköping, Sweden

2 Medical Microbiology, Department of Clinical and Experimental Medicine, Linköping University, Linköping, Sweden

3 Karolinska University Laboratory, Karolinska University Hospital, Solna, Sweden

4 Division of Clinical Microbiology, Department of Laboratory Medicine, Karolinska Institute, Karolinska University Hospital, Huddinge, Sweden standard (defined as the result obtained by at least two of the three PCR methods). The median TAT decreased from 22 hours in 2013 to 2.4 hours in $2015(\mathrm{p}<0.001)$. We conclude that the performance of the Xpert Norovirus assay was excellent, and that the implementation of the analysis as a $24 / 7$ service at all three hospitals in the county has greatly reduced the time to diagnosis which is beneficial for both patients and healthcare providers.

\section{Introduction}

Noroviruses (NoV) are highly infectious non-enveloped RNA viruses and a leading cause of acute gastroenteritis worldwide [1]. There are seven known genogroups, designated genogroup I (GI) to GVII, and over 40 genotypes [2]. The GI and GII are the most important for human infection [3, 4]. NoV infections are typically self-limiting, but may cause severe disease in the most vulnerable, i.e. immunocompromised persons, elderly and small children [5]. NoV is easily transmitted in semi-closed units, such as hospitals and senior care facilities. Rapid and reliable laboratory diagnostics for early identification of outbreaks and sporadic cases are essential for prompt infection control measures and prevention of nosocomial spread [6-10].

Laboratory methods for detection of NoV in clinical samples have evolved over time, and nucleic acid amplification tests (NAAT) have now become the mainstay [11]. Stool is generally regarded as the sample of choice due to the higher viral load as compared to vomitus.

The annual number of NoV samples in Jönköping County, Sweden, is around 1300, and NoV diagnostics used to be centralized at the clinical microbiology laboratory (CML) at the County Hospital Ryhov, Jönköping. The analysis, an inhouse one-step reverse transcription (RT) real-time PCR based 
on Kageyama et al. [12], was performed once to twice daily, and analyses were delayed by transportation and batching of samples. The Xpert ${ }^{\circledR}$ Norovirus assay, a NAAT for the GeneXpert instrument (Cepheid, Sunnyvale, CA, USA), is a single-unit rapid easy-to-use test which can be run on demand and requires little hands-on time. Therefore, the analysis could, after an initial evaluation, be decentralized from the sole CML (open 7.30 a.m. to 7.00 p.m.) to the clinical chemistry laboratories (CCLs) (open $24 \mathrm{~h}$ a day, every day of the week [24/7]) at the three hospitals in our county: Jönköping, Eksjö and Värnamo.

The aim of this study was to evaluate the diagnostic accuracy of the Xpert Norovirus assay and to assess the median turn-around time (TAT) before and after the implementation of the analysis as a $24 / 7$ service.

\section{Materials and methods}

\section{Implementation of the Xpert Norovirus assay at all three hospitals}

After an initial evaluation at the CML, GeneXpert instruments and the Xpert Norovirus assay were set up at the CCLs at all three hospitals in the county during spring 2014. Education of the staff and local validation of the analysis was performed by specialists in molecular diagnostics, who also kept the responsibility for the method's accuracy and the follow-up of external quality controls. Implementation in clinical routine was performed in two steps. From May to November 2014, the analysis was performed daytime in the CCLs in Eksjö and Värnamo, whereas the analysis remained at the CML in Jönköping in order to monitor and identify unexpected problems. During November 2014, the analysis was implemented as a $24 / 7$ service at all three CCLs in the county.

\section{The GeneXpert and the routine method in parallel}

Following the initial evaluation, samples were continuously analyzed in parallel at the CCLs and at the CML in order to follow the quality and performance of the Xpert Norovirus assay in clinical practice. A total number of 276 samples (stool, $n=257$; vomitus, $n=19$ ) from patients with symptoms of acute gastroenterits were included in the study in 2014 2015.

\section{Xpert Norovirus assay with GeneXpert}

All samples were prepared and analyzed with the Xpert Norovirus kit on GeneXpert at the CCLs according to the instructions from the manufacturer. Briefly, a small amount of feces or vomitus was transferred to a vial of sample reagent, vortexed and transferred to the assay cartridge. A sample processing protocol and a probe check control were contained in each cartridge and analyzed in conjunction with each sample. Each cartridge detected NoV GI and GII simultaneously with hydrolysis probes. Samples were interpreted as positive or negative based on their threshold cycle $\left(\mathrm{C}_{\mathrm{t}}\right.$ value $)$ and endpoint signal, via an algorithm in the GeneXpert software, and the presented results included detected GI or GII.

\section{Routine in-house method}

The in-house one-step RT real-time PCR for detection of NoV GI and GII was based on Kageyama et al. [12], with the following modifications: the probe for detection of NoV GII (RING2-TP) was labeled with LC670 to allow multiplex PCR and detection, and a BlackBerry quencher was used instead of Tamra. BlackHole quenchers were used on RING1(a) and RING1(b) for detection of NoV GI (TibMolBiol, Berlin, Germany). RING1(a) was used at 6 pmol, RING1(b) and RING2-TP were used at 2 pmol. Briefly, RNA was extracted from $10 \mu \mathrm{L}$ feces dissolved in $300 \mu \mathrm{L} \mathrm{H}_{2} \mathrm{O}$ or from $300 \mu \mathrm{L}$ of liquid samples. After a brief centrifugation of the samples, viral RNA was extracted using the MagAttract Viral RNA M48 kit (Qiagen, Hilden, Germany) with the BioRobot M48 according to the manufacturer's instructions. One-step RT real-time PCR was performed with $5 \mu \mathrm{L}$ of template in a final reaction volume of $20 \mu \mathrm{L}$ using the LightCycler RNA Amplification HybProbe kit and a LightCycler 480 (Roche, Applied Science, IN, USA). Thermocycling was performed using the following conditions: $55^{\circ} \mathrm{C}$ for $10 \mathrm{~min}$, followed by $95{ }^{\circ} \mathrm{C}$ for $30 \mathrm{~s}, 45$ cycles at $95{ }^{\circ} \mathrm{C}$ for $15 \mathrm{~s}$ and $56^{\circ} \mathrm{C}$ for $45 \mathrm{~s}$. Positive and negative controls were included in each run and manual analysis of the amplification curves was performed.

\section{Samples with discrepant results}

Samples showing discrepant results with the two assays were further analyzed by a third PCR method modified from Nordgren et al. [13, 14]. Viral RNA was extracted from $300 \mu \mathrm{L}$ of $(10 \% v / W)$ fecal supernatant using the MagAttract Viral RNA M48 kit (Qiagen) as described above. Four $\mu$ l of purified RNA was added to a reaction mixture consisting of $10 \mu \mathrm{l}$ of iTaq universal probes reaction mix (BioRad, Stockholm, Sweden), $0.8 \mu \mathrm{L}(10 \mathrm{pmol} / \mu \mathrm{L})$ of each GI and GII primers (NVG1f1b and NVG1rlux, NVG2flux 1 and COG2R), and $0.4 \mu \mathrm{l}$ $(10 \mathrm{pmol} / \mu \mathrm{L}$ of GI and GII probes, $0.5 \mu \mathrm{L}$ of iScript advanced reverse transcriptase and $1.5 \mu \mathrm{L}$ of RNAse free water, to a final volume of $20 \mu \mathrm{l}$. The one-step RT real-time PCR reactions were performed in a 96-well reaction plate using the CFX96 RealTime PCR Detection System (BioRad). The RT real-time PCR was performed under the following conditions: $50^{\circ} \mathrm{C}$ for $10 \mathrm{~min}$ followed by $95^{\circ} \mathrm{C}$ for $3 \mathrm{~min}$ and 45 cycles of $95^{\circ} \mathrm{C}$ for $5 \mathrm{~s}$, and $60^{\circ} \mathrm{C}$ for $30 \mathrm{~s}$. 
Table 1 Comparison between the gold standard test result ${ }^{\mathrm{a}}$ and the Xpert Norovirus assay for detection of noroviruses (NoV)

\begin{tabular}{lllll}
\hline Method of detection & $\begin{array}{l}\text { Gold standard }^{\mathrm{a}} \\
\text { Positive }\end{array}$ & Negative & Total \\
\hline Xpert NoV & Positive & 84 & 13 & 97 \\
& Negative & 0 & 179 & 179 \\
& Total & 84 & 192 & 276 \\
\hline
\end{tabular}

${ }^{\text {a }}$ Gold standard: the result obtained by at least two of the three following methods for detection of NoVs: the Xpert Norovirus assay, the in-house method based on Kageyama et al. [12], and the method based on Nordgren et al. [13, 14].

\section{Turn-around time}

The median TAT was measured before (2013) and after (2015) the GeneXpert@ Norovirus assay was implemented as a 24/7 service at all three hospitals in the county. TAT was measured from the time point that the sample was sent from the healthcare unit to the time point when the laboratory reported the result. The percentage of test results reported within $4 \mathrm{~h}$ was measured from the time point that the sample arrived at the laboratory to the time point when the result was reported. The data were retrieved from DivePort, version 7.0 (Dimensional Insight Inc., Burlington, MA, USA).

\section{Definition of the gold standard}

The gold standard test result was defined as the result obtained by at least two of the following methods: the Xpert Norovirus assay, the in- house PCR method based on Kageyama et al. [12], and the PCR method based on Nordgren et al. [13, 14].

\section{Statistics}

For group comparisons, the Mann-Whitney U-test was used. Data are expressed as median. Statistical analyses were performed using Statistica version 12.7 (StatSoft Inc., Tulsa, OK, USA). $P$-values $<0.05$ were considered significant.

\section{Results}

\section{Comparison between the Xpert Norovirus assay and the gold standard}

The results from the comparison between the Xpert Norovirus assay and the gold standard test results are presented in Table 1 . The sensitivity of the Xpert Norovirus assay was $100 \%$ and the specificity was $93 \%$. The positive predictive value was $87 \%$ and the negative predictive value $100 \%$. Using the Xpert Norovirus assay, 12 samples were positive for GI, and 85 for GII, whereas according to the gold standard, nine samples were positive for GI and 75 for GII. The positive and negative agreement between the Xpert Norovirus assay and the gold standard was $95 \%$.

There were 18 samples (stool, $n=17$; vomitus, $n=1$ ) with discrepant results between the Xpert Norovirus assay and the in-house PCR; all of them showing positive test results with the Xpert Norovirus assay (GI, $n=6$; GII, $n=12$ ), and negative with the in-house PCR. When these 18 samples were analyzed with the third PCR method [13, 14], four showed positive results (GI, $n=3$; GII, $n=1$ ). The mean $\mathrm{C}_{\mathrm{t}}$ value for the 14 samples that had positive results only in the Xpert Norovirus assay was 35.5 (range, 30.4-40.0). Both the inhouse PCR and the Xpert Norovirus assay were able to detect NoV in both stool and vomitus.

\section{Effects on turn-around time}

The overall median TAT from arrival of the samples to the laboratories to available test results decreased from $22 \mathrm{~h}$ in 2013 to $2.4 \mathrm{~h}$ in $2015(p<0.001)$ (Table 2). For samples taken at primary healthcare centers, the median TAT decreased from $38 \mathrm{~h}$ to $14 \mathrm{~h}(p<0.001$, data not shown).

The percentage of analytical test results reported within $4 \mathrm{~h}$ was nearly $100 \%$ after the introduction of the $24 / 7$ service, as compared to $10-30 \%$ before the implementation of the new method (Fig. 1).
Table 2 The median turn-around time (TAT) before and after the GeneXpert ${ }^{\circledR}$ Norovirus assay was implemented at the laboratories of clinical chemistry as a $24 / 7$ service at all three hospitals in the county

\begin{tabular}{|c|c|c|c|c|c|}
\hline \multirow[t]{2}{*}{ Setting } & \multicolumn{2}{|l|}{2013} & \multicolumn{2}{|l|}{2015} & \multirow[t]{2}{*}{ P-value } \\
\hline & TAT; hours (n) & IQR & TAT; hours (n) & IQR & \\
\hline All clients & $22(1124)$ & $14-30$ & $2.4(1289)$ & $2.0-4.2$ & $* * *$ \\
\hline All clients excl. PHC & $20(933)$ & $11-26$ & $2.3(1123)$ & $2.0-3.2$ & $* * *$ \\
\hline Jönköping & $19(583)$ & $7.8-25$ & $2.4(778)$ & $2.0-3.4$ & $* * *$ \\
\hline Eksjö & $20(140)$ & $14-26$ & $2.0(161)$ & $1.9-2.5$ & $* * *$ \\
\hline Värnamo & 24 (194) & $19-29$ & $2.2(195)$ & $2.0-3.6$ & $* * *$ \\
\hline PHC only & 38 (191) & $27-48$ & $14(166)$ & $6.4-22$ & $* * *$ \\
\hline
\end{tabular}

PHC primary healthcare centre, TAT median turn-around time from sampling to available test result, IQR interquartile range

*** $P<0.001$ 
Fig. 1 Percentage of test results reported within 4 hours from sample arrival at the laboratory before and after the GeneXpert ${ }^{\circledR}$ Norovirus assay was implemented at the laboratories of clinical chemistry as a $24 / 7$ service at all three hospitals in the county. May 2014: analysis was performed during the daytime with GeneXpert. November 2014: analysis of $\mathrm{NoV}$ was implemented as a $24 / 7$ service

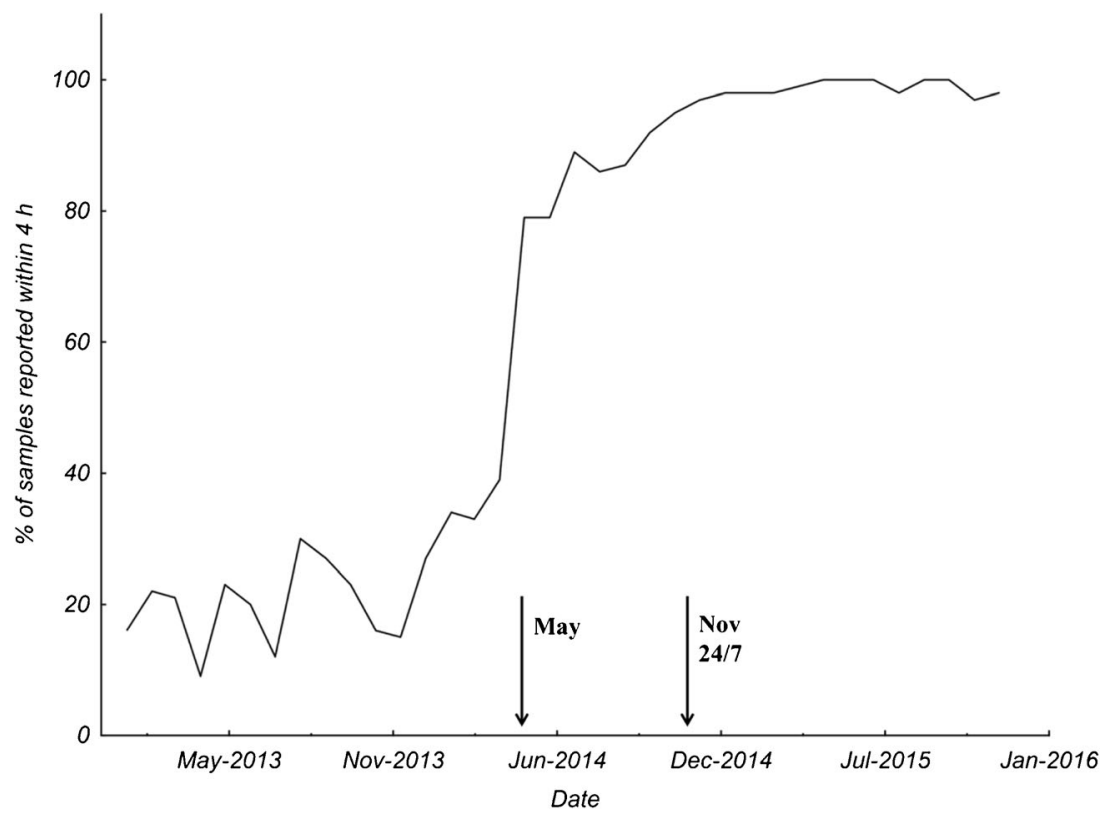

\section{Discussion}

$\mathrm{NoV}$ is the most common cause of gastroenteritis in all age groups globally [15]. A rapid and accurate diagnosis is crucial for appropriate infection prevention measures and reduces the necessity of additional diagnostic procedures.

The results of the Xpert Norovirus assay presented here indicate high performance regarding detection and differentiation of the prominent NoVs genogroups, which has also been shown by others [11]. In fact, the Xpert Norovirus assay seemed to have a higher sensitivity and to be more reliable in detecting both NoV GI and GII than the in-house PCR [12] as well as the third PCR $[13,14]$. The samples that showed positive test results only with the Xpert assay had high $C_{t}$ values, indicating a low viral load in the samples or possibly unspecific nucleic acid amplification. However, we think that unspecific PCR products are a less plausible explanation, since all patients had symptoms of acute gastroenteritis.

The median TAT was substantially reduced when singleunit analysis on demand was practicable and the same 24/7 laboratory service could be provided at all three hospitals. Rapid identification of $\mathrm{NoV}$ cases facilitates adequate infection control measures, as well as planning of medical staff resources and is likely to reduce the healthcare costs, although we have not studied these economic aspects in this work.

The Xpert Norovirus assay is rapid and easy to use, and requires little hands-on time. Manual interpretation and registration of test results have now been replaced by interpretation by the Xpert software and automatic data transfer from the GeneXpert instrument to the laboratory information system. Single sample analysis reduces TAT since no batching of samples is necessary, and furthermore, it decreases the risk for contamination and mix-up of samples.
Even though we see several advantages in the decentralization of easy-to-use assays, like the Xpert Norovirus assay, to facilities open $24 / 7$, we believe that it is important that specialists with experience from molecular virology maintain the responsibility for validation and follow up of the diagnostic performance, and that in-house PCR methods are available for complementary analysis when required.

In conclusion, we found that the diagnostic performance of the Xpert Norovirus assay was excellent, and since the analytical platform and the ease of performing the test allowed its implementation as a 24/7 service at all hospitals in our county, it has entailed a significant time gain for the patients and the healthcare providers, as well as a more efficient, automated and less stressful work flow in the laboratory.

Acknowledgements The authors would like to thank Dr. Jonas Swanberg, Clinical Microbiology, Jönköping, for help with retrieval of TAT data. We would also like to thank the staff at the laboratories of clinical chemistry at the hospitals in Jönköping, Eksjö and Värnamo for pleasant and fruitful collaboration.

\section{Compliance with ethical standards}

Funding The study was funded by the Laboratory of Clinical Microbiology, Laboratory Medicine, Region Jönköping County, Sweden.

Conflict of interest The authors declare that they have no conflict of interest.

Ethical approval The study was approved by the head of Laboratory Medicine, Region Jönköping County, Sweden, as part of the diagnostic development of the laboratory.

Informed consent For this study, rest material of clinical samples (stool and vomitus) submitted for routine testing was used. Upon routine testing samples were anonymized and during the initial technical evaluation, the 
results from the Xpert Norovirus assay were not disclosed, and therefore, did not have an impact on the management of the patients. TATs were retrieved retrospectively and anonymously from the laboratory information system. Thus, due to the study design, formal consent was not required.

Open Access This article is distributed under the terms of the Creative Commons Attribution 4.0 International License (http:// creativecommons.org/licenses/by/4.0/), which permits unrestricted use, distribution, and reproduction in any medium, provided you give appropriate credit to the original author(s) and the source, provide a link to the Creative Commons license, and indicate if changes were made.

\section{References}

1. Glass RI, Parashar UD, Estes MK (2009) Norovirus gastroenteritis. N Engl J Med 361:1776-1785

2. Vinjé $\mathbf{J}$ (2015) Advances in laboratory methods for detection and typing of norovirus. J Clin Microbiol 53:373-381

3. Lysén M, Thorhagen M, Brytting M, Hjertqvist M, Andersson Y (2009) Genetic diversity among food-borne and waterborne norovirus strains causing outbreaks in Sweden. J Clin Microbiol 47:2411-2418

4. Matthews J, Dickey B, Miller R, Felzer J, Dawson B (2012) The epidemiology of published norovirus outbreaks: a systematic review of risk factors associated with attack rate and genogroup. Epidemiol Infect 140:1161-1172

5. Ramani S, Atmar RL, Estes MK (2014) Epidemiology of human noroviruses and updates on vaccine development. Curr Opin Gastroenterol 30(1):25-33

6. Cheng FW, Leung TF, Lai RW, Chan PK, Hon EK, Ng PC (2006) Rapid control of norovirus gastroenteritis outbreak in an acute paediatric ward. Acta Paediatr 95(5):581-586

7. Cheng VC, Wong LM, Tai JW, Chan JE, To KK, Li IW et al (2011) Prevention of nosocomial transmission of norovirus by strategic infection control measures. Infect Control Hosp Epidemiol 32(3):229-237
8. MacCannell T, Umscheid CA, Agarwal RK, Lee I, Kuntz G, Stevenson KB, Healthcare Infection Control Practices Advisory Committee-HICPAC (2011) Guideline for the prevention and control of norovirus gastroenteritis outbreaks in healthcare settings. Infect Control Hosp Epidemiol 32:939-969

9. Division of Viral Diseases, National Center for Immunization and Respiratory Diseases, Centers for Disease Control and Prevention (2011) Updated norovirus outbreak management and disease prevention guidelines. MMWR Recom Rep RR-3:1-18

10. The Swedish Public Health Agency (2014) Vinterkräksjuka i vården. Kunskapsunderlag för att minska spridningen av norovirus. Available at www.folkhalsomyndigheten.se/publicerat-material/. Accessed 15 May 2017

11. Gonzalez MD, Langley LC, Buchan BW, Faron ML, Maier M, Templeton K et al (2016) Multicenter evaluation of the Xpert norovirus assay for detection of norovirus genogroups I and II in fecal specimens. J Clin Microbiol 54:142-147

12. Kageyama T, Kojima S, Shinohara M, Uchida K, Fukushi S, Hoshino FB et al (2003) Broadly reactive and highly sensitive assay for Norwalk-like viruses based on real-time quantitative reverse transcription-PCR. J Clin Microbiol 41(4):1548-1557

13. Nordgren J, Bucardo F, Dienus O, Svensson L, Lindgren PE (2008) Novel light-upon-extension real-time PCR assays for detection and quantification of genogroup I and II noroviruses in clinical specimens. J Clin Microbiol 46:164-170

14. Oluwatoyin Japhet M, Adeyemi Adesina O, Famurewa O, Svensson L, Nordgren J (2012) Molecular epidemiology of rotavirus and norovirus in Ile-Ife, Nigeria: high prevalence of G12P[8] rotavirus strains and detection of a rare norovirus genotype. J Med Virol 84(9):1489-1496

15. Ahmed SM, Hall AJ, Robinson AE, Verhoef L, Premkumar P, Parashar UD et al (2014) Global prevalence of norovirus in cases of gastroenteritis: a systematic review and meta-analysis. Lancet Infect Dis 14:725-730 